\title{
Biorefinery via Catalytic Upgraded Fast Pyrolysis of Biomass
}

\author{
Ferruccio Trifirò
}

Dipartimento di “Chimica Industriale Toso Montanari” Università di Bologna Viale Riosrgimento 4, 40136 Bologna, Italy

Corresponding Author Email: ferruccio.trifiro@unibo.it

https://doi.org/10.18280/ti-ijes.652-417

Received: 18 March 2021

Accepted: 7 May 2021

\section{Keywords:}

biomass, pyrolysi, fast-pyrolysis, catalyticfast-pyrolysis, hydropyrolysis,

hydrodeoxygenation, co-pyrolysis

\begin{abstract}
Energy can be produced from biomass by biochemical, biological and thermal process. Pyrolysis is a thermal process that operate at temperature between 400-600C in absence of oxygen or with very low amount, to produce a bio-oil, char and gas. The best technology is fast pyrolysis that produce higher amount of liquid bio-oil, particularly $75 \%$ of liquid, -at $500^{\circ} \mathrm{C}$ without oxygen, contact time lesser $2 \mathrm{sec}$ a drying of biomass till $10 \%$, with dimension of particles of biomass of $3 \mathrm{~mm}$, using mainly bubbling fluid bed, However the bio-oil obtained with fast pyrolysis present a lot drawbacks: it presents a high amount of oxygen, high acidity, high viscosity, high moisture and chemical instability. Fast pyrolysis can be upgraded operating in the presence of a catalyst (in-situ) or with a downstream catalytic reactor to the that one of fast pyrolysis (ex situ). Besides it is possible upgrade the bio-oil transforming it in fuels and chemical products realizing the catalytic pyrolysis in presence of $\mathrm{H} 2$ (hydropyrolysis) or realizing hydrodeoxygenation reactions downstream the fast pyrolysis or using as reductants wastes from plastics, from rubber of tires or from organic wastes in order to realize a catalytic co-pyrolysis.
\end{abstract}

\section{INTRODUCTION}

With the demand of energy and re-utilization of wastes, the renewable lignocellulosic biomass, are today investigated to produce energy and to resolve environment problems. There are three generations of biomass: first-generation biomass includes starches (e.g., grains and potatoes) and carbohydrates (e.g., sugar cane and sugar beet) and they are also for food. From first-generation biomass is possible to produce bioethanol and from oils it is possible to produce diesel. The second-generation biomass includes farm products (e.g., herbs, wood, straw, and rice husks) that an ice husks) that are not available as food, and mainly are lignocellulosic biomass The third-generation biomass are algae that contains lipids.

Biomass can be converted to fuel and to chemical products by biological, chemical and thermal technologies. An example of the biological routes is the production of bioethanol from sugar cane by fermentation, an example of the chemical route is the esterification of vegetable oil to produce biodiesel; thermal technologies are combustion gasification and pyrolysis, and hydrothermal technologies. Pyrolysis it seems the most interesting technology. In this note will be examined many technologies to improve pyrolysis to produce fuels: the fast pyrolysis, the "in- situ- catalytic fast pyrolysis, the ex- situ catalytic- fast pyrolysis, the hydropyrolysis, the hydrodeoxygenation and the catalytic fast co-pyrolysis [1-3].

\section{PRE-TREATMENT OF BIOMASS}

The pre-treatment of biomass is necessary to convert them into a more suitable feedstocks for pyrolysis and to improve the amount and the properties of the obtained bio-oil. The different methods of pre-treatment used are: physical methods (grinding and densification), thermal treatments at low temperature (torrefaction), chemical treatments (with acidic solutions or alkali metals) and biological methods [4-11]. The "Grinding" pre-treatment reduce the biomass particles sizes and density, improving the heat flow between the substrates and it decreases the degree of polymerization and crystallization of biomass components during the pyrolysis process and therefore influence the amount and the composition of bio-oil obtained. Particularly in fluid bed reactor of the fast pyrolysis treatment, the particle size of biomass must be $<2 \mathrm{~mm}$ and in circulating fluid bed $<6 \mathrm{~mm}$. The "Densification" pre-treatment is used because one of negative aspect of using biomass as feedstock for chemistry is its low density that could make difficult its transport and its store, and could lead to slow heat transfer trough the particles during pyrolysis. Densification is realized with a compaction process of biomass by applying mechanical forces to produce solid pellets or briquettes. The densification changes the density, the moisture content and the energy contents of the biomass and it increases heating and mass transfer efficiency of the pyrolysis process. The results of densification are: the increase of the amount of hydrocarbons in bio-oil and the increase the mass transfer efficiency of the pyrolysis process. The "Dry Torrefaction" is a thermal pre-treatment between $200-300^{\circ} \mathrm{C}$ at low heating rate in an inert atmosphere. During torrefaction the fibrous structure and tenacity of the biomass is changed which leads in decreasing the activation energy of the pyrolysis process. With a pre-treatment at $\mathrm{T} 200-235^{\circ} \mathrm{C}$ there is a degradation of hemicellulose structure, at temperature between $235-275^{\circ} \mathrm{C}$ there is a depolymerization of the hemicellulose and of several bonds of cellulose that are also degraded, at temperature between $275-300^{\circ} \mathrm{C}$ there is a completely degradation of hemicellulose and almost completely of the cellulose and it starts the degradation of the 
lignin. The torrefaction decreases the oxygen content of the bio-oil and improve the biomass structure to produce a better biofuel. The "Wet Torrefaction" is the pre-treatment in presence of water at temperature of $180-260^{\circ} \mathrm{C}$. The "Chemical methods" treatment with acid alkali and hot water to remove the minerals and the alkali metals from biomass moisture and impurities of biomass improving the properties of bio-oil obtained. Besides the acid pre-treatment causes significant changes in the structure and increases the average pore diameter and energy density. It is well known that biomass mainly consists of lignin, cellulose and hemicellulose. The proportion of these three components in different types of biomass could influence the pyrolytic behaviour and cause difference in the chemical compositions of bio-oils. The biomass can contain inorganic minerals as phosphate, carbonates sulphates and chlorides and minerals. The minerals can present catalytic properties and they can influence the pyrolysis of biomass. Besides the insoluble inorganic species can remain in the bio-oil and can start polymerization or condensation and therefore its presence is not favourable for biooil properties. The acid pre-treatment is generally realized with sulphuric acid. The acid pre-treatment can also eliminate some lead compounds that are present in the biomass. The alkali pre-treatment is realized with $\mathrm{NaOH}, \mathrm{NH}_{4} \mathrm{OH}, \mathrm{Ca}(\mathrm{OH})_{2}$ and improve the biomass structure especially remove the lignin component and improve cellulose digestibility. The alkali treatment of lignocellulose biomass leads to a solubilization of lignin and hemicellulose and remove the inorganic species present in the biomass.

The "Hot water extraction" is realized at temperature around $200^{\circ} \mathrm{C}$ for a contact time of $15 \mathrm{~min}$. and it is useful for breaking some linkages of hemiacetal linkages.

\section{FAST PYROLYSIS}

Pyrolysis is a thermochemical transformation in absence of oxygen to transform the biomass mainly in bio-oil and in small amount in char and gas depending on heating rate reaction temperature and residence time and it can be divided in slow pyrolysis, intermediate pyrolysis, flash pyrolysis and fast pyrolysis. In Slow pyrolysis the contact time can be hours and days and it is used essentially to produce biochar.

Intermediate pyrolysis operates with auger reactor with heating rate with few minute, flash pyrolysis operates at temperature of $300-700^{\circ} \mathrm{C}$ to produce essentially gas [12].

The characteristic of fast pyrolysis are: moderate temperature $400-600^{\circ} \mathrm{C}$ slow residence time $<5 \mathrm{sec}$, high heating rate $10-200^{\circ} \mathrm{C} / \mathrm{s}$ and the best reactor are fluidized bed and circulating fluid bed reactor and with a rapid cooling of vapours. The fast pyrolysis produces more liquid, there is more bio-oil, than the other pyrolysis technologies. The fast pyrolysis, there is the not catalytic fast pyrolysis produce too much oxygenated products with high water content.

\section{CATALYTIC FAST PYROLYSIS}

Catalytic upgrading of pyrolysis (CFP) vapours can be carried out either in-situ pyrolysis step or ex-situ catalytic step. In-situ CFP pyrolysis and catalytic upgrading occurring in a one-step with a single reactor process, while in ex-situ CFP it is required a transfer of the pyrolysis vapours from the initial pyrolysis reactor to a secondary reactor for catalytic upgrading [13-18].

\subsection{In situ Catalytic Fast Pyrolysis}

"In- situ fast catalytic pyrolysis" (called also catalytic fast pyrolysis) is the liquefaction of woody biomass by pyrolysis and its catalytic upgrading from oxygenates compounds to aromatics in the same reactor. The bio-oil obtained by "In situ catalytic fast pyrolysis" (in -situ CFP) is better of that one obtained by simple fast pyrolysis (FP) in terms of heating value, oxygen content, viscosity and stability [19-23]. The evolved vapours obtained with "in situ CFP" are converted in lesser reactive compounds than those produced by noncatalytic fast pyrolysis and char and coke and catalyst are separated by cyclone present after the reactor and the char and coke after separation from catalyst are send to the combustion to produce energy and the catalyst is recycled. Solids removal prior to the eventual ex- situ upgrading step provides an advantage with respect to catalyst stability and choices minimization of the deactivation of the catalysts. The vapors are transformed in incondensable gas and liquid and an organic and aqueous liquid are formed. The organic liquid after separation from catalyst is send predominantly to hydrodeoxygenation reactor to produce biofuel (gas, gasoline, diesel and jet fuel). Aqueous liquid which contains organic acids can be used to produce $\mathrm{H}_{2}$ used in hydrodeoxygenation. Advantages of" In situ CFP" in confront with "Ex- situ CFP" are lesser capital cost due to a simpler process configuration. The negative aspects of "In situ CFP are the higher ratio catalyst /biomass, that it is necessary in order to have the same level of deoxygenation and the deactivation of the catalyst owing to adsorption of char. In-situ CFP technology aromatics and olefins form as bio-oil. The activities of all catalysts decreased with the increase in reuse cycles, but could be regenerated by using a simple calcination process. The most studied catalysts in catalytic pyrolysis of biomass have been. zeolites, mainly ZSM-5 and other zeolites such as MCM-41, MFI, Beta, Y, and mordenite. An alternative to zeolites is to use transition metals ( $\mathrm{Ni}, \mathrm{Fe}, \mathrm{Co}$ ) loaded on different supports. The role of the catalysts is to decrease the content of oxygenated compounds in the bio-oil, transforming them in aliphatic and aromatic hydrocarbons.

\subsection{Ex Situ fast pyrolysis}

"Ex situ catalytic fast pyrolysis" (ex-situ CFP) or "Two stages catalytic fast pyrolysis" is constituted by a fast pyrolysis reactor and a down- stream catalytic reactor for upgrading the bio-oil [19-23]. In ex- situ CFP the two reactions of transformation of biomass are separated and the optimization of the pyrolysis conditions and of the catalyst performance occurs separately [24-27]. In ex- situ CFP "biomass rapidly transform in a fast pyrolysis reactor at approximately $500^{\circ} \mathrm{C}$, followed by the separation of produced solids (char and mineral matter) from vapours (including permanent gases) and the vapours are then sent to an ex- situ catalytic reactor for upgrading. The upgrading in the second reactor involves deoxygenation, hydrogenation and carbon-carbon coupling in the presence of a catalyst. In ex-situ CP it occurs independent control of pyrolysis and upgrading reaction conditions because it is possible to change the temperature and the contact time of the pyrolysis reactor and the type of catalyst and of the catalytic reactor. In the pyrolysis reactor is used a fluidized bed reactor, in the second stage where it is realized the catalytic reaction is used a fixed bed reactor and in "ex situ CFP" not only ZSM-5 as catalyst it used but also Pt supported catalysts 
can be used. In fact, in "Ex-situ catalytic fast pyrolysis" char produced during pyrolysis which contain most of the ash, can be removed before the catalytic reactor, and this it is the reason that it allows the use of fixed bed reactor without deactivating the catalyst, with the possibility to use also Pt based avoiding the problems of attrition of the catalyst occurred in fluid bed. In "Ex situ CFP" it is possible to use lower ratio catalyst/ biomass to obtain the same level of deoxygenation and to operate at high contact time than in situ and at lower or higher temperature according to the used catalyst. In "Ex-situ CFP and "in.-situ CFP" similar amounts of aromatics + olefins are obtained, but more olefins it is possible to obtain, in "ex- situ CFP "because it is possible to operate at higher temperature.

\section{CATALYTIC FAST CO-PYROLYSIS}

In CFP there are two problems, the presence of oxygenates and the deactivation of the catalyst due to the formation of tars, it has been proposed, in order to give a solution to these problems, to realize the catalytic pyrolysis of biomass together with hydrogen containing feedstocks. Although CFP of biomass can promote the generation of aromatics and the removal of oxygen in pyrolysis products, it leads to hydrogen deficiency and limits the content of hydrocarbons. In order to make up for this defect, an hydrogen-rich material is added to the biomass to realize "Catalytic fast co-pyrolysis" (CFCP) and this solution is considered an effective way to alleviate the hydrogen shortage and reduce the amount of coke [28-36].

The hydrogen containing feedstocks are plastic wastes (polyethylene, polypropylene, polystyrene, polyethylene terephthalate and polycarbonates), rubber from waste tires, organic wastes (household), marine wastes, seaweeds and sewage sludge and oily sludge. The addition of these feedstocks to the biomass resolves the hydrogen deficiency and facilitates deoxygenation, limit the deactivation and it decreases the formation of tars and also the formation of higher amount of polyaromatics. Besides the transformation of these wastes into useful products resolve also environmental problems realizing a circular economy. The catalytic fast copyrolysis of biomass is a combination of fast catalytic pyrolysis and co-pyrolysis, via the introduction of appropriate raw materials to supply enough hydrogen to avoid the deactivation of catalysts. Similarly, to the common catalytic pyrolysis of biomass, reactions in the catalytic co-pyrolysis are also performed in an inert atmosphere. Acid and base catalysts are used at temperature between $500-600^{\circ} \mathrm{C}$ with a ratio biomass to wastes generally from 1 to 0,5 . The co-pyrolysis of plastics with biomass is a promising chemical recycling method to effectively collect energy from waste plastics. Furthermore, plastics have high carbon and hydrogen contents with little oxygen, which makes the co-pyrolysis of waste plastics and biomass potentially valuable for the up-gradation of bio-oil. while the formation of alkane and alkene groups was promoted in the co-pyrolysis of cellulose and high-density polyethylene.

\section{PYROLYSIS OF BIOMASS AND HYDROGENATION OF BIO-OIL}

Based on an assessment of the fuel price per mass of oil equivalent, it was concluded that a viable route for renewable liquid fuel production is fast pyrolysis coupled with catalytic hydrodeoxygenation (HDO). While fast pyrolysis is used to increase the biomass energy density by producing a liquid product commonly referred to as bio-oil, which can be transported more easily than solid biomass, catalytic HDO is used to enhance the fuel properties through oxygen removal in a $\mathrm{H}_{2}$ atmosphere using a suitable catalyst. Another promising technology is the coupling of fast pyrolysis and HDO in catalytic fast hydropyrolysis, where the HDO is performed directly in the pyrolysis reactor [37-38]. The $\mathrm{H}_{2}$ required for these processes could possibly be provided by electrolysis of water powered by wind or solar energy. There are main technologies to realize hydrogenation of bio-oil to transform it in fuels: Hydopyrolysis (Catalytic fast hydropyrolysis) by realizing fast pyrolysis of biomass and hydrogenation of formed bio-oil in the same reactor; hydrodeoxygenation by realizing in the first reactor the fast pyrolysis or the catalytic fast pyrolysis and in a second or in a second and third reactor hydrogenation.

\subsection{Hydropyrolysis}

Hydropyrolysis (CFHP) is the technology that it uses an hydrogenation catalyst together with a fast pyrolysis reaction and $\mathrm{H}_{2}$, in order to reduce the amount of aromatics transforming them in alkanes, to reduce the char and to produce methane as gas. Hydopyrolysis of biomass is the combination of fast pyrolysis and catalytic hydrodehoxygenation of biomass to produce directly renewable diesel and gasoline from biomass [39-41] The presence of hydrogen in the CFHP reactor increases carbon efficiency by shifting reaction pathway from decarbonylation and decarboxylation to dehydration, thus removing oxygen in the form of water. Inclusion of a ZSM-5 catalyst in the CFHP reactor assists in pyrolysis vapor deoxygenation and char reduction, while the presence of a transition metal, such as $\mathrm{Ni}$ or Ru may assist in hydrogenation reactions working at 35 bar. Compared to catalytic fast pyrolysis, CFHP present higher yields of hydrocarbons and much slower catalyst deactivation due to coking decreasing. Yields and process economics are equivalent to those of fast pyrolysis followed by hydrodecoxygenation. Another advantage of CFHP is that the hydrogenation process is exothermic and the pyrolysis is endothermic. Besides the intermediate products of pyrolysis do not polymerize because they are immediate hydrogenated avoiding their polymerization. Some other catalysts in CFHP are NI/MCM41 and MCM41, Pd- ZSM-5, and $\mathrm{CoMoAl}_{2} \mathrm{O}_{3}$.

HCFP produce two liquid phases: an organic containing a mixture of hydrocarbons and acqueous phase, a solid (coke) and gas.

Catalytic fast hydropyrolysis (CFHP), which combines fast pyrolysis with catalytic hydrodeoxygenation in a single reactor, eliminates the need for reheating condensed bio-oil, lowers side reactions, in order to produce a stable oil with low oxygen content, $\mathrm{H} / \mathrm{C}$ ratio, and heating value comparable to fossil fuels. In order to realize CFHP it is necessary to optimize the operating conditions (temperature, the $\mathrm{H}_{2}$ pressure, and residence time) and the catalyst formulation to maximize oil yield and minimize cracking, coke formation, and catalyst deactivation,

\subsection{Hydrodeoxygenation}

This technology is the realization of biomass pyrolysis followed by hydrodeoxygenation used to upgrade fast 
pyrolysis bio-oil, as oxygenates present in bio-oil react with hydrogen to produce a stable hydrocarbon fuel and water, which is removed by separation. Single stage HDO of condensed bio-oil is unsuited for commercial scale bio-oil upgrading, as the coking and polymerization, which occurs upon re-heating of the bio-oil, rapidly deactivates the catalyst and plugs the reactor [42-45]. Dual or multiple stage HDO has shown more promising results, as the most reactive oxygenates can be stabilized at low temperature prior to deep HDO for full deoxygenation. Coke formation could be minimized by maintaining a high hydrogen pressure during catalytic fast hydropyrolysis. If instead HDO is performed on condensed oil in a separate step, coke formation should be limited by multiple stage processing. Here, the reactive cellulose and hemicellulose derived oxygenates are hydrogenated in the first part of the HDO reactor at low temperature (from below $80^{\circ} \mathrm{C}$ to $180^{\circ} \mathrm{C}$ ), and the final part of the HDO reactor cracks and deoxygenates the refractory lignin derived oxygenates at high temperatures $\left(>300^{\circ} \mathrm{C}\right)$. Regarding the more traditional one stage HDO with a single reactor operated at $250-400^{\circ} \mathrm{C}$, coking during heating of the oil will be so severe that catalyst deactivation, low energy recovery of the oil, and plugging make the process infeasible. Due to the thermal instability of bio-oil, catalytic fast hydropyrolysis with immediate product stabilization seems an alternative, promising approach compared to sequential non-catalytic fast pyrolysis and single stage HDO of the condensed oil. Catalytic fast hydropyrolysis can be coupled with downstream HDO of the pyrolysis vapor for further product upgrade, prior to condensation of the produced oil. Another option is to couple non-catalytic fast pyrolysis with downstream HDO of the pyrolysis vapor. However, for all three options (catalytic fast hydropyrolysis with and without downstream HDO, and fast pyrolysis with downstream HDO), several tasks remain. One example of HDO is a two-stage hydrodeoxygenation process for pyrolysis bio-oil: the first step of the process is the catalytic hydrogenation of the thermally unstable bio-oil at a temperature of $270{ }^{\circ} \mathrm{C}$ and pressure of 136 atm using Co$\mathrm{Mo} / \mathrm{Al}_{2} \mathrm{O}_{3}$ or $\mathrm{Ni}-\mathrm{Mo} / \mathrm{Al}_{2} \mathrm{O}_{3}$ catalysts that were sulfides firstly in the reactor. The thermally unstable bio-oil compounds usually decompose, forming cock that directly plugs the reactors. The main hydrodeoxygenation reaction primarily occurs in the second step, which involves a catalytic hydrogenation reaction but at a higher temperature, reaching up to $400^{\circ} \mathrm{C}$, and at the same pressure using the same catalyst. Different groups of catalysts have been investigated for the HDO of fast pyrolysis bio-oil, which can be classified into sulphides, transition metals, phosphides, and other catalysts (carbides and nitrides).

\section{CONCLUSIONS}

The industrial application of fast pyrolysis is the up-grading of bio-oil by hydrodeoxygenation and by co-pyrolysis with plastics in order to obtain fuels similar those ones obtained with petroleum. Catalytic HDO is a promising technique for upgrading bio-oil, and much research has been devoted to developing and understanding catalyst systems as well as reaction and deactivation mechanisms. Particularly deactivation is a major issue in HDO. Recent studies revealed that catalytic co-pyrolysis promoted the production of upgraded bio-oil via reduction of oxygenated compounds and increased the production of aromatic hydrocarbons. There are several steps to commercialize the co-pyrolysis process including the application of high feedstock/catalyst ratio, development of the catalyst that suppresses coke formation, Pyrolysis is considered the most promising way to convert biomass to fuels. Upgrading biomass pyrolysis oil is essential to produce high quality hydrocarbon fuels. The high oxygen content of bio-oil leads to its undesirable properties, such as chemical instability and a strong tendency to re-polymerize. Acidity, low heating value, high viscosity and water content are not conductive to making bio-oils useful as fuels.

\section{REFERENCES}

[1] Bridgwater, A.V. (2012). Review of fast pyrolysis of biomass and product upgrading. Biomass and Bioenergy, 38: 68-94.

https://doi.org/10.1016/j.biombioe.2011.01.048

[2] Kargbo, H., Harris, J.S., Phan, A.N. (2021). "Drop-in" fuel production from biomass: Critical review on technoeconomic feasibility and sustainability. Renewable and Sustainable Energy Reviews, 135: 110168. https://doi.org/10.1016/j.rser.2020.110168

[3] Trifirò, F. (2019). Fuels from biomass. Italian Journal of Engineering Science, 163(1): 85-93.

[4] Brown, R.C. (2019). Thermochemical processing of biomass: conversion into fuels, chemicals and power. John Wiley \& Sons., 175-206.

[5] Gunukula, S., Daigneault, A., Boateng, A.A., Mullen, C. A., DeSisto, W.J., Wheeler, M.C. (2019). Influence of upstream, distributed biomass-densifying technologies on the economics of biofuel production. Fuel, 249: 326333. https://doi.org/10.1016/j.fuel.2019.03.079

[6] Hu, X., Gholizadeh, M. (2019). Biomass pyrolysis: A review of the process development and challenges from initial researches up to the commercialisation stage. Journal of Energy Chemistry, 39: 109-143. https://doi.org/10.1016/j.jechem.2019.01.024

[7] Alper, K., Tekin, K., Karagöz, S., Ragauskas, A.J. (2020). Sustainable energy and fuels from biomass: a review focusing on hydrothermal biomass processing. Sustainable Energy \& Fuels, 4(9): 4390-4414. https://doi.org/10.1039/D0SE00784F

[8] Tan, H., Wang, S. (2009). Experimental study of the effects of acid-washing pretreatment on biomass pyrolysis. Journal of Fuel Chemistry and Technology, 37(6): 668-672. https://doi.org/10.1016/S18725813(10)60014-X

[9] Oudenhoven, S.R.G., van der Ham, A.G., van den Berg, H., Westerhof, R.J.M., Kersten, S.R. (2016). Using pyrolytic acid leaching as a pretreatment step in a biomass fast pyrolysis plant: Process design and economic evaluation. Biomass and Bioenergy, 95: 388404. https://doi.org/10.1016/j.biombioe.2016.07.003

[10] Chen, D., Cen, K., Jing, X., Gao, J., Li, C., Ma, Z. (2017). An approach for upgrading biomass and pyrolysis product quality using a combination of aqueous phase bio-oil washing and torrefaction pretreatment. Bioresource Technology, 233: 150-158. https://doi.org/10.1016/j.biortech.2017.02.120

[11] Chen, H., Liu, J., Chang, X., Chen, D., Xue, Y., Liu, P., Han, S. (2017). A review on the pretreatment of lignocellulose for high-value chemicals. Fuel Processing Technology,

160:

196-206. 
https://doi.org/10.1016/j.fuproc.2016.12.007

[12] Kostetskyy, P., Broadbelt, L.J. (2020). Progress in modeling of biomass fast pyrolysis: A review. Energy \& Fuels, 34(12): 15195-15216. https://doi.org/10.1021/acs.energyfuels.0c02295

[13] Rahman, MM., Liu, R., Cai, J. (2018). Catalytic fast pyrolysis of biomass over zeolites for high quality biooil-A review. Fuel Processing Technology, 180: 32-46. https://doi.org/10.1016/j.fuproc.2018.08.002

[14] Baruah, J., Nath, B.K., Sharma, R., Kumar, S., Deka, R.C., Baruah, D.C., Kalita, E. (2018). Recent trends in the pretreatment of lignocellulosic biomass for valueadded products. Frontiers in Energy Research, 6: 141. https://doi.org/10.3389/fenrg.2018.00141

[15] Kumar, R., Strezov, V., Weldekidan, H., He, J., Singh, S., Kan, T., Dastjerdi, B. (2020). Lignocellulose biomass pyrolysis for bio-oil production: A review of biomass pre-treatment methods for production of drop-in fuels. Renewable and Sustainable Energy Reviews, 123: 109763. https://doi.org/10.1016/j.rser.2020.109763

[16] Dai, L., Wang, Y., Liu, Y., He, C., Ruan, R., Yu, Z., Wu, Q. (2020). A review on selective production of valueadded chemicals via catalytic pyrolysis of lignocellulosic biomass. Science of the Total Environment, 749: 142386. https://doi.org/10.1016/j.scitotenv.2020.142386

[17] Iliopoulou, E.F., Triantafyllidis, K.S., Lappas, A.A. (2019). Overview of catalytic upgrading of biomass pyrolysis vapors toward the production of fuels and highvalue chemicals. Wiley Interdisciplinary Reviews: Energy and Environment, 8(1): e322. https://doi.org/10.1002/wene.322

[18] Luna-Murillo, B., Pala, M., Paioni, A.L., Baldus, M., Ronsse, F., Prins, W., Weckhuysen, B.M. (2020). Catalytic fast pyrolysis of biomass: Catalyst characterization reveals the feed-dependent deactivation of a technical ZSM-5-based catalyst. ACS Sustainable Chemistry \& Engineering, 9(1): 291-304. https://doi.org/10.1021/acssuschemeng.0c07153

[19] Gamliel, D.P., Du, S., Bollas, G.M., Valla, J.A. (2015). Investigation of in situ and ex situ catalytic pyrolysis of miscanthus $\times$ giganteus using a PyGC-MS microsystem and comparison with a bench-scale spouted-bed reactor. Bioresource Technology, 191: 187-196. https://doi.org/10.1016/j.biortech.2015.04.129

[20] Castello, D., He, S., Ruiz, M.P., Westerhof, R.J., Heeres, H.J., Seshan, K., Kersten, S.R. (2019). Is it possible to increase the oil yield of catalytic pyrolysis of biomass? A study using commercially-available acid and basic catalysts in ex-situ and in-situ modus. Journal of Analytical and Applied Pyrolysis, 137: 77-85. https://doi.org/10.1016/j.jaap.2018.11.012

[21] Raymundo, L.M., Mullen, C.A., Strahan, G.D., Boateng, A.A., Trierweiler, J.O. (2019). Deoxygenation of biomass pyrolysis vapors via in situ and ex situ thermal and biochar promoted upgrading. Energy \& Fuels, 33(3): 2197-2207.

https://doi.org/10.1021/acs.energyfuels.8b03281

[22] Shirazi, Y., Viamajala, S., Varanasi, S. (2020). In situ and ex situ catalytic pyrolysis of microalgae and integration with pyrolytic fractionation. Frontiers in Chemistry, 8: 786.

[23] Li, S., Cheng, S., Takahashi, F., Cross, J.S. (2020). Upgrading crude bio-oil by in situ and ex situ catalytic pyrolysis through ZSM-5, Ni2Fe3, and Ni2Fe3/ZSM-5:
Yield, component, and quantum mechanism. Journal of Renewable and Sustainable Energy, 12(5): 053101. https://doi.org/10.1063/5.0009689

[24] Wan, S., Wang, Y. (2014). A review on ex situ catalytic fast pyrolysis of biomass. Frontiers of Chemical Science and Engineering, 8(3): 280-294. https://doi.org/10.1007/s11705-014-1436-8

[25] Ruddy, D.A., Schaidle, J.A., Ferrell III, J.R., Wang, J., Moens, L., Hensley, J.E. (2014). Recent advances in heterogeneous catalysts for bio-oil upgrading via "ex situ catalytic fast pyrolysis": Catalyst development through the study of model compounds. Green Chemistry, 16(2): 454-490.

[26] Hu, C., Xiao, R., Zhang, H. (2017). Ex-situ catalytic fast pyrolysis of biomass over HZSM-5 in a two-stage fluidized-bed/fixed-bed combination reactor. Bioresource Technology, 243: 1133-1140. https://doi.org/10.1016/j.biortech.2017.07.011

[27] Iisa, K., French, R.J., Orton, K.A., Dutta, A., Schaidle, J.A. (2017). Production of low-oxygen bio-oil via ex situ catalytic fast pyrolysis and hydrotreating. Fuel, 207: 413422. https://doi.org/10.1016/j.fuel.2017.06.098

[28] Zhang, X., Lei, H., Zhu, L., Zhu, X., Qian, M., Yadavalli, G., Chen, S. (2016). Thermal behavior and kinetic study for catalytic co-pyrolysis of biomass with plastics. Bioresource Technology, 220: 233-238. https://doi.org/10.1016/j.biortech.2016.08.068

[29] Zhang, X., Lei, H., Chen, S., Wu, J. (2016). Catalytic copyrolysis of lignocellulosic biomass with polymers: a critical review. Green Chemistry, 18(15): 4145-4169. https://doi.org/10.1039/C6GC00911E

[30] Ahmed, M.H., Batalha, N., Mahmudul, H.M., Perkins, G., Konarova, M. (2020). A review on advanced catalytic co-pyrolysis of biomass and hydrogen-rich feedstock: Insights into synergistic effect, catalyst development and reaction mechanism. Bioresource Technology, 310: 123457. https://doi.org/10.1016/j.biortech.2020.123457

[31] Ryu, H.W., Kim, D.H., Jae, J., Lam, S.S., Park, E.D., Park, Y.K. (2020). Recent advances in catalytic copyrolysis of biomass and plastic waste for the production of petroleum-like hydrocarbons. Bioresource Technology, 310 : 123473. https://doi.org/10.1016/j.biortech.2020.123473

[32] Miskolczi, N., Zsinka, V., Tóth, O., Eller, Z., Gao, N., Cui, Q., Bobek, J. (2020). Co-pyrolysis-reforming of biomass and residues from waste polymer pyrolysis for $\mathrm{CO} 2$ reduction and syngas enhancement. Chemical Engineering Transactions, 81: 1195-1200. https://doi.org/10.3303/CET2081200

[33] Liu, J., Hou, Q., Ju, M., Ji, P., Sun, Q., Li, W. (2020). Biomass pyrolysis technology by catalytic fast pyrolysis, catalytic co-pyrolysis and microwave-assisted pyrolysis: A review. Catalysts, $10(7)$ : 742. https://doi.org/10.3390/catal10070742

[34] Praveen Kumar, K., Srinivas, S. (2019). Catalytic copyrolysis of biomass and plastics (polypropylene and polystyrene) using spent FCC catalyst. Energy \& Fuels, 34(1): 460-473. https://doi.org/10.1021/acs.energyfuels.9b03135

[35] Park, Y. Siddiqui, H.Z., Karagoz, S. et al. (2021). Insitu catalytic co-pyrolysis of kukerite oil shake with black one wood over acid zeolite. Journal of Analytical and Applied $\quad$ Pyrolysis, 155 : 105050. https://doi.org/10.1016/j.jaap.2021.105050 
[36] Hu, Y., Wang, H., Lakshmikandan, M., Wang, S., Wang, Q., He, Z., Abomohra, A.E.F. (2020). Catalytic copyrolysis of seaweeds and cellulose using mixed ZSM-5 and MCM-41 for enhanced crude bio-oil production. Journal of Thermal Analysis and Calorimetry, 143: 827842. https://doi.org/10.1007/s10973-020-09291-w

[37] Dabros, T.M., Stummann, M.Z., Høj, M., Jensen, P.A., Grunwaldt, J.D., Gabrielsen, J., Jensen, A.D. (2018). Transportation fuels from biomass fast pyrolysis, catalytic hydrodeoxygenation, and catalytic fast hydropyrolysis. Progress in Energy and Combustion Science, 68: 268-309. https://doi.org/10.1016/j.pecs.2018.05.002

[38] Zupko, R. (2019). Life cycle assessment of the production of gasoline and diesel from forest residues using integrated hydropyrolysis and hydroconversion. The International Journal of Life Cycle Assessment, 24(10): 1793-1804. https://doi.org/10.1007/s11367-01901616-8

[39] Balagurumurthy, B., Bhaskar, T. (2014). Hydropyrolysis of lignocellulosic biomass: state of the art review. Biomass Conversion and Biorefinery, 4(1): 67-75. https://doi.org/10.1007/s13399-013-0086-2

[40] Stummann, M.Z., Elevera, E., Hansen, A.B., Hansen, L.P., Beato, P., Davidsen, B., Høj, M. (2020). Catalytic hydropyrolysis of biomass using supported CoMo
catalysts-Effect of metal loading and support acidity. Fuel, 264: 116807. https://doi.org/10.1016/j.fuel.2019.116807

[41] Stummann, M.Z. Hoj, M. (2021). A perspective of catalytic hydropyrolyiis of bioassay. Renewable and Sustainable Energy Reviews, 143(110960): 1-10.

[42] Nolte, M.W., Saraeian, A., Shanks, B.H. (2017). Hydrodeoxygenation of cellulose pyrolysis model compounds using molybdenum oxide and low pressure hydrogen. Green Chemistry, 19(15): 3654-3664. https://doi.org/10.1039/C7GC01477E

[43] Nolte, M.W., Saraeian, A., Shanks, B.H. (2017). Hydrodeoxygenataion of cellulose pyrolysis model compounds using molybdenum oxide and low pressure hydrogen. Green Chemistry, 19(15): 3654-3664. https://doi.org/10.1039/C7GC01477E

[44] Attia, M., Farag, S., Chaouki, J. (2020). Upgrading of Oils from Biomass and Waste: Catalytic Hydrodeoxygenation. Catalysts, 10(12): 1381. https://doi.org/10.3390/catal10121381

[45] Han, D., Yin, W., Arslan, A., Liu, T., Zheng, Y., Xia, S. (2020). Stabilization of fast pyrolysis liquids from biomass by mild catalytic hydrotreatment: Model compound study. Catalysts, 10(4): 402. https://doi.org/10.3390/catal10040402 